lines the evidence for a ketogenic response by term infants to blood glucose concentrations as low as $<2.0 \mathrm{mmol} / \mathrm{l}$. Therefore, it is not possible to claim that counter-regulation has failed if only blood glucose concentrations are measured. We feel that the presence of symptoms or the features of an underlying disorder are more important determinants of treatment than the blood glucose concentration alone, and would suggest that treating all asymptomatic term infants with blood glucose concentrations transiently below $2.0 \mathrm{mmol} / \mathrm{l}$ with intravenous glucose is over aggressive management.

If clinicians are not comfortable with blood glucose concentrations as low as this, we suggest that the first line of treatment should be to increase enteral feed volumes and frequency with formula supplementation of breast feeds, and check postprandial increases in blood glucose concentration, rather than to separate mother and baby and commence invasive management. In fact, we do not agree that enteral feeds should be withheld from hypoglycaemic infants who have previously tolerated milk feeds, as there is no scientific support for Dr Mehta's speculation in section C (1) (iii) and he has not examined the effect of withholding enteral feeds on ketone body production. Rather, milk contains more energy/ml than $10 \%$ dextrose and its high fat content will provide substrate for ketogenesis. In addition, there is published evidence that enteral feeding may stimulate glucagon release and ketone body production. 45

We agree that adequate intakes of intravenous glucose or enteral milk prevent hypoglycaemia in most preterm infants, but point out that there is a high prevalence of hypoglycaemia in preterm infants who are fluid restricted. ${ }^{5}$

In summary, we feel that it is inappropriate and potentially confusing to base the management of neonatal hypoglycaemia on hypotheses which are not fully scientifically tested. However, it should be noted that there is agreement between the two papers on the identification of groups at risk of failure of metabolic adaptation.

J M HAWDON $M$ P WARD PLATT A AYNSLEY-GREEN

1 Hawdon JM, Aynsley-Green A, Ward Platt MP. The role of pancreatic insulin secretion in neonatal glucoregulation. I. 274-9.

2 Hawdon JM, Aynsley-Green A, Bartlett K, Ward Platt MP. The role of pancreatic insulin secretion in neonatal glucoregulation. II. Infants with disordered blood glucose homoeostasis. Arch Dis Child 1993; 68: 280-5.

3 Hume R, Burchell A. Abnormal expression of glucose-6 phosphatase in preterm infants. Arch Dis Child 1993; 68: 202-4.

4 Lucas A, Bloom SR, Aynsley-Green A. Metabolic and endocrine consequences of depriving preterm infants of enteral nutrition. Acta Paediatr Scand 1983; 72: 245-9.

5 Hawdon JM, Ward Platt MP, Aynsley-Green A. Patterns of metabolic adaptation for preterm and term infants in the metabolic adaptation for preterm and term infants in

6 Lucas A, Morley R, Cole T. Adverse neurodevelopmental outcome of moderate neonatal hypoglycaemia. $B M \mathcal{F} 1988$; 297: 1304-8.
Institute of Child

Health, University of

Liverpool

J M Hawdon

Princess Mary

Maternity Hospital,

Newcastle upon Tyne

M P Ward Platt

Institute of Child Health, University of London

A Aynsley-Green

Correspondence to: Dr J M Hawdon, Institute of Child Health, Roya Liverpool Children's Hospital Alder Hey, Eaton Road, Liverpool L12 2AP.

\title{
Prevention and management of neonatal hypoglycaemia
}

\author{
J M Hawdon, M P Ward Platt, A Aynsley-Green
}

Few topics in clinical paediatrics cause more confusion than the management of neonatal hypoglycaemia. Although it has been acknowledged as a clinical problem for many decades, ${ }^{1}$ its diagnosis and management continue to be controversial issues, with disagreement even between staff on the same nursery. ${ }^{2-4}$ This review presents our conspectus of the clinical situations in which hypoglycaemia most commonly occurs and the management of the condition. Rare disorders, such as inborn errors of metabolism and complex hormone deficiencies, which may present with hypoglycaemia are not discussed.

Neonatal hypoglycaemia most commonly occurs when the normal processes of metabolic adaptation after birth fail to occur. These processes enable the healthy infant to meet two major metabolic challenges. First, the need to maintain an adequate circulating concentrations of glucose or alternative fuels to supply the body's organs, especially the brain, and second, the need to adapt to a new form of nutrition, namely intermittent feeding with milk. As the blood glucose concentration falls after the cutting of the umbilical cord and until milk feeding is established, the baby is entirely dependent upon its own resources to maintain fuel supply. Glycogenolysis is initiated as the initial counter-regulatory process. Once the glycogen stores are exhausted, however, substrates must be mobilised from body protein and fat stores so that gluconeogenesis can occur. These processes are induced by the counter-regulatory hormones (glucagon, catecholamines, growth hormone, and cortisol).

Although much is known of the basic biochemical processes which underlie these phenomena, ${ }^{56}$ clinical controversy exists surrounding the criteria for diagnosis of hypoglycaemia in the neonatal period, suitable monitoring policies, and the practical implications for management. This discussion first relates to the diagnosis of hypoglycaemia in general neonatal practice, then deals with monitoring and clinical management in specific circumstances. 
Diagnosis of neonatal hypoglycaemia Immediate emphasis must be placed on the importance of accurate diagnostic methods. Several authors have shown that reagent strips are too inaccurate for the diagnosis of neonatal hypoglycaemia. ${ }^{127}$ We believe that, wherever possible, accurate laboratory blood glucose measurements should be made for neonatal blood glucose monitoring and the diagnosis of hypoglycaemia. The introduction of a bench top blood glucose electrode (YSI 2300 Stat Plus, YSI Ltd) in our neonatal nursery has markedly facilitated blood glucose monitoring without adding an excessive technical workload, in a way analogous to the instantaneous, accurate analysis of blood gas concentrations in the nursery sideroom.

In the discussion of the diagnosis of hypoglycaemia, it is essential to consider which numerical value represents hypoglycaemia, and in order to do this the significance of low blood glucose concentrations must be understood. These are two important questions which are difficult to answer in the face of current knowledge. Of particular importance is the recognition that previous definitions of hypoglycaemia were based on statistical analysis of blood glucose concentrations in the first few days after birth, with values that were almost certainly dependent on the management policies of the day. ${ }^{189}$ Improved obstetric management and the early introduction of milk feeding have created a very different pattern of metabolic adaptation to that seen 30 years ago. ${ }^{10}$

In adults, a counter-regulatory hormonal and metabolic response occurs and symptoms of neuroglycopenia are evident at blood glucose concentrations of 4.0 and $2.7 \mathrm{mmol} / \mathrm{l}$ respectively. ${ }^{11}$ In a small number of term infants, neurological dysfunction was demonstrated when blood glucose concentrations fell below $2.6 \mathrm{mmol} / \mathrm{l}$, whether or not the infant had symptoms, and, moreover, resolution of normoglycaemia did not restore normal neurological function immediately. ${ }^{12}$ Of more concern is the finding in a retrospective study that the neurological outcome of preterm infants was adversely affected if the babies had experienced blood glucose concentrations below $2.6 \mathrm{mmol} / \mathrm{l}$ on five or more days during the neonatal period. ${ }^{13}$ From these data, it is tempting to propose that a blood glucose concentration below $2.6 \mathrm{mmol} / 1$ should be taken as the lowest which is acceptable in all neonates. However, we have challenged this view, suggesting that hypoglycaemia is a continuum, its biological effects varying according to the availability of alternative fuels, such as ketone bodies, for brain metabolism, and according to the presence of other compounding clinical problems such as birth asphyxia, polycythaemia, hypocalcaemia, and hypercarbia. ${ }^{1} 1013$

These dilemmas may be resolved only by a major research study in which glucose and other fuel concentrations are measured concurrently with direct measurements of brain function in different groups of newborn infants, and these data then related to long term neurological outcome. Such a study would allow the formulation of precise guidelines for monitoring and intervention in each category of term and preterm infants. However, until such a study has been performed, we must consider a pragmatic approach to the management of hypoglycaemia, and this is based upon our findings regarding circulating fuel concentrations in infants managed according to current policies in our nurseries.

\section{Metabolic adaptation in healthy, appropriate birth weight for gestational age (AGA) infants}

Early and recent work has demonstrated that after the abrupt cessation of placental nutrition at birth, transient hypoglycaemia is almost universal in all newborn mammals. However in human infants, even if enteral feeds are withheld, this phenomenon is self limiting and blood glucose concentrations rise. ${ }^{9} 1014$ Therefore, this early self limiting period of hypoglycaemia cannot be considered to be pathological, and there is little practical value in measuring the blood glucose concentrations of asymptomatic babies in the first two postnatal hours. After this period, blood glucose concentrations below $2.6 \mathrm{mmol} / \mathrm{l}$ may recur in many healthy babies, particularly those who are demand fed, with long between feed intervals, and those who are breast fed. ${ }^{10}$ However, a marked ketogenic response to low blood glucose concentrations has been demonstrated in these infants, and evidence from animal studies suggests that this response is protective of neurological function as ketone bodies are important glucose sparing cerebral fuels. ${ }^{10} 15-18$ Therefore, we consider the monitoring of blood glucose concentrations in healthy, appropriately grown neonates to be unnecessary, and potentially harmful to parental wellbeing and the successful establishment of breast feeding. ${ }^{19} 20$

\section{Metabolic adaptation in preterm infants (<36 weeks' gestation)}

Like term babies, preterm babies will experience a rapid fall in blood glucose concentration after delivery, but, unlike term infants they are less able to mount the counter-regulatory response whereby gluconeogenesis and ketogenesis occur. ${ }^{1021}$ In addition, preterm infants $<32$ weeks' gestation are at increased risk of other neurological insults, such as cerebral ischaemia. Therefore, clinical attention to blood glucose concentrations may be regarded as being more important when dealing with preterm babies, and, in the light of the findings of Lucas et al, ${ }^{13}$ we propose that concentrations $<2.6 \mathrm{mmol} / \mathrm{l}$ should be avoided. This view is contrary to older beliefs that small babies can be expected to tolerate lower blood glucose concentrations than large ones. ${ }^{1}$

However, current management policies of early provision of enteral and/or intravenous fluids, usually ensure that this early hypoglycaemia is rapidly corrected, and, provided 
the exogenous supply of energy is sufficient, hypoglycaemia will not subsequently recur. ${ }^{10}$ This supply of energy should be instituted immediately after birth and the initial prescription of enteral or intravenous fluids should not be influenced by an immediate postnatal blood glucose concentration. Therefore, the measurement of blood glucose concentration immediately after birth adds little clinical information and should not affect management. It is much more rational and of greater importance to ensure that the prescribed energy supply is adequate by accurately measuring the blood glucose concentration 1-2 hours after intravenous or enteral feeding has been commenced, so that necessary adjustments can be made.

In our experience, neonatal hypoglycaemia can be prevented in preterm babies by the provision of enteral and/or intravenous feeds (as formula milk and $10 \%$ dextrose respectively) at rates of at least $100 \mathrm{ml} / \mathrm{kg} /$ day. ${ }^{10}$ However, some sick infants will not tolerate these volumes and, as described previously, blood glucose monitoring should confirm that their rates of glucose supply are adequate. If blood glucose concentrations are low $(<2.6 \mathrm{mmol} / \mathrm{l})$, this suggests that glucose demand exceeds supply. Therefore, glucose infusion rates should be increased, either by increasing the concentration of the glucose solution or by increasing the intravenous fluid infusion rate. Neonatal blood glucose concentrations correlate closely with glucose infusion rates. ${ }^{22}$ If there are symptoms of hypoglycaemia (fits or reduced level of consciousness) a small bolus dose of $10 \%$ intravenous glucose $(3 \mathrm{ml} / \mathrm{kg}$ ) may be given, but should always be followed immediately by a glucose infusion at an adequate rate to meet the baby's ongoing glucose requirement (at least $5 \mathrm{mg}$ glucose $/ \mathrm{kg} / \mathrm{min}$ ). Bolus injections of large volumes of hypertonic glucose solutions should be avoided because they cause a rapid rise in blood glucose concentrations, which may be harmful to neurological function and may be followed by rebound hypoglycaemia. In older children such treatment has been shown to cause cerebral oedema or even death. ${ }^{23}$ In addition clinical experience suggests that such high glucose concentrations are caustic to fragile neonatal veins.

Once adequate blood glucose concentrations are achieved, it is not necessary to measure blood glucose concentrations repeatedly in a clinically stable baby unless there is a reduction in exogenous energy supply. As there is a risk of 'rebound hypoglycaemia', reductions of intravenous glucose infusion rates should be gradual and 'tissued' drips should be resited promptly. Clearly, any change in clinical condition or reduction in fluid or nutrient intake should be followed by blood glucose measurement to ensure such changes have not resulted in hypoglycaemia.

Finally, attention should be drawn to the importance of enteral milk feeding. Milk formulas provide more energy/ml than $10 \%$ dextrose, and supply important non-glucose fuels, which have a glucose sparing role in neurological function. There is evidence that enteral milk feeding enhances the vital processes of metabolic adaptation by promoting ketogenesis and gut maturation. ${ }^{1024}$ In immature babies who may have reduced milk absorption secondary to delayed gastric emptying and reduced gut motility, the adequacy of exclusive enteral feeding to maintain normoglycaemia should be confirmed by accurate blood glucose measurement until these measurements are stable. Both prefeed and postprandial values should be considered, as there is a feed related cyclical variation in blood glucose concentrations. ${ }^{15}$

\section{Metabolic adaptation in small for gestational age (SGA) infants}

We propose that the SGA infants of most concern are those whose birth weight falls below the third centile or those who have clinically obvious wasting of adipose tissue and muscle (regardless of their birthweight centile), but with preservation of head growth. For the latter group of babies, measurement of the mid-arm circumference: head circumference ratio has been shown to be useful in predicting those who are at risk for metabolic problems. ${ }^{25-27}$

SGA infants are at risk of the adverse effects of hypoglycaemia by virtue of impaired gluconeogenesis and ketogenesis, both immediately after birth and in response to persistent hypoglycaemia. ${ }^{27-30}$ As the patterns of metabolic adaptation and nutritional requirements of preterm SGA infants are similar to those of preterm AGA infants, this section will focus on the management of the term SGA neonate.

SGA infants are at risk of adverse neurological sequelae of neonatal hypoglycaemia for a number of reasons: chronic hypoglycaemia, acidosis and hypoxia may have occurred in utero $^{31}$ 32; perinatal asphyxia is more common $^{33}$; there is an inability to mount a ketogenic response to hypoglycaemia, so that there is no provision of alternative fuels for brain metabolism ${ }^{27}$; and enteral feed tolerance may be poor, with an increased risk of necrotising enterocolitis. ${ }^{33}$ Therefore, accurate blood glucose monitoring should be performed in this group of infants. Both prefeed and postprandial values should be considered, as there is a feed related cyclical variation in blood glucose concentrations. ${ }^{15}$

As with preterm infants, it is important to ensure the early provision of exogenous calories, to curtail the early postnatal hypoglycaemic period, and to prevent subsequent hypoglycaemia. It is our experience that this can usually be achieved by regular, formula milk feeds every three hours at volumes of at least $120 \mathrm{ml} / \mathrm{kg} /$ day. As breast milk appears to be more ketogenic than formula milk, ${ }^{10}$ it is important that breast feeding is encouraged when this is the mother's wish, by allowing the baby to suckle at each feed time, and then by supplementing the breast feed with formula milk, by gavage if necessary. It should be noted that the energy content of formula milk is 
approximately $2750 \mathrm{~kJ} / \mathrm{l}$, while that of $10 \%$ dextrose is $1600 \mathrm{~kJ} / \mathrm{l}$. If necessary high energy milk formulas may be used, for example those designed for preterm infants, or energy supplements (for example, Duocal, Scientific Hospital Supplies) may be added to enteral milk feeds. By these means, it should be possible to meet the energy needs of most full term SGA babies with enteral milk feeds without recourse to intravenous glucose.

When babies cannot tolerate these enteral feed volumes, or if the above regimen fails to prevent hypoglycaemia (blood glucose concentration $<2.6 \mathrm{mmol} / \mathrm{l}$ ), an intravenous glucose infusion may be required. Hypoglycaemia is usually rapidly reversed by intravenous glucose infusion, at a rate of $5 \mathrm{mg} / \mathrm{kg} / \mathrm{min} \quad(=72$ $\mathrm{ml} / \mathrm{kg} /$ day of $10 \%$ dextrose) without a bolus glucose injection. ${ }^{34}$ This rate can then be adjusted, up or down, depending on blood glucose concentrations. Because of the beneficial effects of enteral feeding, milk feeds must not be discontinued or reduced when intravenous fluids are given (unless, of course, the infant is developing necrotising enterocolitis). Our practice is to feed the baby with as much milk as is tolerated, and to infuse glucose at a rate sufficient to prevent hypoglycaemia, so that the fluid regimen is tailored to each baby.

Finally, there are some SGA infants who have persistent hypoglycaemia or excessively high glucose requirements. Glucose infusions may be required for up to one week, and rapid reductions or wide swings in glucose infusion rates should be avoided. By maximising enteral feed intakes and gradually reducing intravenous infusion rates, almost all infants eventually achieve the ability to control their own blood glucose concentrations. Additional treatments, such as intravenous glucagon, may be of value and are discussed in detail elsewhere. ${ }^{34-36}$

\section{Infants with hyperinsulinism}

This phenomenon is believed to be commonly found in the infant of the poorly controlled diabetic mother, but may occur in association with rarer conditions, such as BeckwithWeidemann syndrome and islet cell dysregulation syndrome (nesidioblastosis) whose management is reviewed elsewhere. ${ }^{37}$ In these latter conditions, hypoglycaemia is common but, despite plentiful adipose tissue stores, the lipolytic and ketogenic responses are suppressed by high circulating insulin concentrations.

Although many studies have outlined the possible mechanisms of early hypoglycaemia in the infant of the diabetic mother, ${ }^{38-40}$ there have been no studies which have investigated the occurrence of hypoglycaemia, and, of greater importance, the ketogenic response beyond the immediate postnatal period, particularly in the context of improved maternal diabetic control. However, it is our clinical experience that neonatal hypoglycaemia is now rare in insulin dependent mothers managed according to current practices.

It should be pointed out that previous diagnoses of 'neonatal hyperinsulinism' in these insulin dependent mothers were made with reference to insulin/glucose relationships in older subjects. We have recently demonstrated that even healthy, asymptomatic term neonates have insulin/glucose relationships which differ markedly from those of older children and that, for neonates, plasma insulin and blood glucose concentrations are poorly related and baseline insulin secretion appears to be high. ${ }^{41}$ Therefore, we suggest that the diagnosis should only be made on clinical grounds, that is a high glucose requirement to maintain normoglycaemia, together with biochemical evidence of an absent lipolytic and ketogenic response to hypoglycaemia, with reference to data from healthy neonatal subjects. We suggest that, using these criteria hyperinsulinism is now rare in insulin dependent mothers and that these babies could be treated as healthy term babies, provided they are asymptomatic. This is the hypothesis to be addressed in an ongoing research study.

\section{Infants with perinatal asphyxia}

Like small for gestational age infants, these babies may be at increased risk of hypoglycaemia which may compound other severe neurological insults. In addition, we have found that under these circumstances there is no ketogenic response to hypoglycaemia (unpublished data), and some of these infants have unusually high glucose requirements $(>12 \mathrm{mg} / \mathrm{kg} / \mathrm{min}){ }^{42}$ The exogenous supply of fuels to minimise cerebral dysfunction must be ensured but often these infants are fluid restricted and hypoglycaemia may occur. Therefore, as with preterm and SGA babies, accurate blood glucose measurement is mandatory and the supply of exogenous energy, as concentrated glucose solutions if necessary, must be maintained. However, we have found that these infants are also at risk of hyperglycaemia which may be secondary to increased stress hormone release (unpublished data), and suggest that blood glucose monitoring and carefully prescribed glucose infusion rates should be utilised to prevent both extremes of loss of glycaemic control. The same general considerations apply to any infant who has a severe systemic illness.

In summary, there are some groups of neonates who are at risk, first, of an increased incidence of hypoglycaemia and, second, adverse neurological sequelae when hypoglycaemia occurs. Even within these groups, each infant will have a different level of risk, and some of the protective mechanisms, such as changes in cerebral blood flow or ketone body production, cannot be easily quantified. Therefore, at the present level of knowledge, we recommend that for the following groups of infants blood glucose concentrations should be monitored, until they are stable within an optimal range, that is blood glucose concentrations below $2.6 \mathrm{mmol} / \mathrm{l}$ and above $10 \mathrm{mmol} / \mathrm{l}$ should be avoided: preterm babies, especially when sick; SGA babies; infants with proved hyperinsulinism; and infants with perinatal asphyxia or with other systemic illnesses (figure). It is 


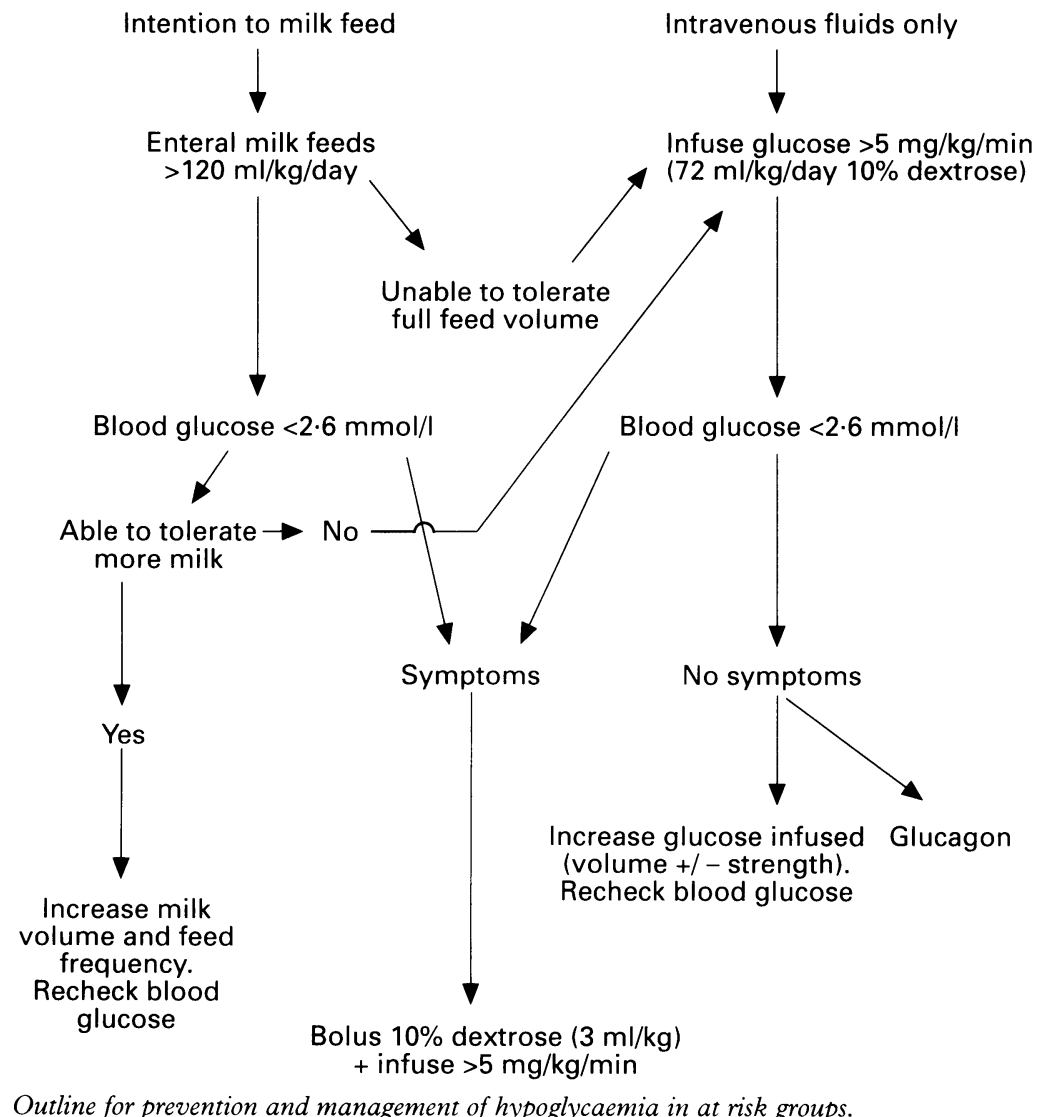

possible that further scientific investigation, correlating circulating fuel availability with neurological function and neurodevelopmental outcome, will identify more accurately those groups who are most at risk, so that more appropriate management policies can be applied.

Dr Hawdon was supported by the Scientific and Research Committee of Newcastle Health Authority and by a Foundation Committee of Newcastle Health Authority and by a
for the Study of Infant Deaths training fellowship.

1 Aynsley-Green A. Glucose: a fuel for thought! $\mathcal{f}$ Pediat Child Health 1991; 27: 21-30

2 Cornblath $M$, Schwartz R. Hypoglycemia in the neonate. In: Cornblath M, Schwartz R, eds. Disorders of carbohydrate metabolism in infancy. Philadelphia: W B Saunders, 1991 .

3 Koh THHG, Eyre JA, Aynsley-Green A. Neonatal hypoglycaemia - the controversy regarding definition. Arch Dis Child 1988; 63: 1386-8.

4 Cornblath M, Schwartz R, Aynsley-Green A, Lloyd JK. Hypoglycemia in infancy: The need for a rational definition. A Ciba Foundation discussion meeting. Pediatrics 1990; 85: 834-7.

5 Ogata ES. Carbohydrate metabolism in the fetus and neonate and altered neonatal glucoregulation. Pediatr Clin North Am 1986; 33: 25-44

6 Girard J. Metabolic adaptation to change of nutrition at birth. Biol Neonate 1990; 58 (suppl): 3-15.

7 Holtrop PC, Madison KA, Kieckle FL, Karcher RE, Batton DG. A comparison of chromogen test strip (Chemstrip bg) and serum glucose values in newborns. $A m \mathcal{F}$ Dis Child 1990; 144: 183-5.

8 Cornblath $\mathrm{M}$, Reisner $\mathrm{SH}$. Blood glucose in the neonate and its clinical significance. $N$ Engl $\mathcal{F}$ Med 1965; 273: $378-80$.

9 Srinivasan G, Pildes RS, Cattamanchi G, Viora S, Lilien LD. Plasma glucose values in normal neonates: a new look. F Pediatr 1986; 109: 114-7.

10 Hawdon JM, Ward Platt MP, Aynsley-Green A. Patterns of metabolic adaptation for preterm and term neonates in the first postnatal week. Arch Dis Child 1992; 67 357-65.

11 de Feo P, Gallai V, Mazzotta G, et al. Modest decrements in plasma glucose concentration cause early impairment in cognitive function and later activation of glucose counterregulation in the absence of hypoglycemic symptoms in normal man. f Clin Invest 1988; 82: 436-41.

12 Koh THHG, Aynsley-Green A, Tarbit M, Eyre JA. Neura dysfunction during hypoglycaemia. Arch Dis Child 1988 63: $1353-8$

13 Lucas A, Morley R, Cole TJ. Adverse neurodevelopmental outcome of moderate neonatal hypoglycaemia. $B M f$ 1988; 297: 1304-8.
14 Cornblath $\mathrm{M}$, Reisner SH. Blood glucose in the neonate and its clinical significance. $N$ Engl $\mathcal{F}$ Med 1965; 273:

15 Lucas A, Boyes S, Bloom SR, Aynsley-Green A. Metabolic and endocrine responses to a milk feed in 6 day old term infants: differences between breast and cow's milk formula feeding. Acta Paediatr Scand 1981; 70: 195-200.

16 Edmond J, Auestad N, Robbins RA, Bergstrom JD. Ketone body metabolism in the neonate: development and the effect of diet. Federal Proceedings 1985; 44: 2359-64.

17 Medina JM, Fernandez E, Bolans JP, Vicario C, Arizmendi L. Fuel supply to the brain during the early postnatal period. In: Cuezva JM, Pascual-Leone AM, Patel MS, eds. New York: Plenum, 1990.

18 Yager JY, Heitjan DF, Towfighi J, Vannucci RC. Effect of insulin-induced and fasting hypoglycaemia on perinatal hypoxic-ischemic brain damage. Pediatr Res 1992; 31: $138-42$.

19 Hawdon JM. Neonatal hypoglycaemia: the consequences of admission to the special care nursery. Child Health 1993 Feb: $48-51$

20 Hawdon JM, Ward Platt MP, Aynsley-Green A. Neonatal hypoglycaemia - blood glucose monitoring and infant feeding. Midwifery 1993; 9: 3-6.

21 Cowett RM, Schwartz R. The role of hepatic control of glucose homeostasis in the etiology of neonatal hypo and hyperglycemia. Semin Perinatol 1979; 3: 327

22 Hawdon JM, Aynsley-Green A, Bartlett K, Ward Platt MP. The role of pancreatic insulin secretion in neonatal glucoregulation. II Infants with disordered blood glucose coregulation. II Infants with disordered bl

23 Shah A, Stanhope R, Matthew D. Hazards of pharmacological tests of growth hormone secretion in childhood. $B M Y$ 1992; 304: 173-4

24 Lucas A, Bloom SR, Aynsley-Green A. Gastrointestinal peptides and the adaptation to extrauterine nutrition. Can f Physiol Pharmacol 1985; 63: 527-37.

25 Sasanow SR, Georgieff MK, Pereira GR. Mid arm circumference and mid arm circumference/head circumference ratios: standard curves for anthropometric assessment of neonatal nutritional status. $f$ Pediatr 1986; 109. 311-5.

26 Georgieff $M K$, Sasanow SR, Chockalingham UM, Pereira $\mathrm{GR}$. A comparison of the mid arm circumference/head
circumference ratio and ponderal index for the evaluation circumference ratio and ponderal index for the evaluation of newborn infants after abnormal in
Acta Paediatr Scand 1988; 77: 214-9.

27 Hawdon JM, Ward Platt MP. Metabolic adaptation in smal for gestational age infants. Arch Dis Child 1993; 68 $262-8$.

28 Hay WW. Fetal and neonatal glucose homeostasis and their relation to the small for gestational age infant. Semin Perinatol 1984; 8: 101-16.

29 Jones RAK, Roberton NRC. Problems of the small for dates baby. Clin Obstet Gynecol 1984; 11: 499-524.

30 de Leeuw R, de Vries IJ. Hypoglycemia in small for dates newborn infants. Pediatrics 1976; 58: 18-22.

31 Economides DL, Nicolaides $\mathrm{KH}$. Blood glucose and oxygen tension levels in small for gestational age fetuses. $A m \mathcal{F}$ Obstet Gynecol 1989; 160: 385-9.

32 Hawdon JM, Ward Platt MP, McPhail S, Cameron $\mathrm{H}$ Walkinshaw SA. Prediction of impaired metabolic adaptation by antenatal Doppler studies in small for gestational age fetuses. Arch Dis Child 1992; 67: 789-92.

33 Hackett GA, Campbell S, Gamsu H, Cohen-Oberlech T, Pearce JMF. Doppler studies in the growth retarded fetus and prediction of neonatal necrotising enterocolitis, haemorrhage and neonatal morbidity. BMF 1987; 294: 13-6.

34 Hawdon JM, Aynsley-Green A, Ward Platt MP. Neonatal blood glucose concentrations: metabolic effects of intravenous glucagon and intragastric medium chain triglycvenous glucagon and intragastric medi
eride. Arch Dis Child 1993; 68: 255-61.

35 Mehta A, Wootton R, Cheng KL, Penfold P, Halliday D, Stacey TE. Effect of diazoxide or glucagon on hepatic glucose production rate during extreme hypoglycaemia. Arch Dis Child 1987; 62: 924-30.

36 Carter PE, Lloyd DJ, Duffty P. The use of glucagon in the management of hypoglycaemia in the small for gestationa age infant. A report of 25 cases. Arch Dis Child 1988; 63: 1264-7.

37 Aynsley-Green A, Soltesz G. Disorders of blood glucose homeostasis in the neonate. In: Roberton NRC, ed. Neonatology. Edinburgh: Churchill Livingstone, 1992

38 Pedersen J, Bejsen-Moller B, Poulsen H. Blood sugar in newborn infants of diabetic mothers. Acta Endocrinol (Copenh) 1954; 15: 33.

$39 \mathrm{Kuhl} C$ Andersen GE Hestel J, Molsted-Pedersen L. Metabolic events in infants of diabetic mothers during first 24 hours after birth. I Changes in plasma glucose, insulin and glucagon. Acta Paediatr Scand 1982; 71: 19-25.

40 Andersen O, Hestel J, Scholonder L, Kuhl C. Influence of maternal plasma glucose concentration at delivery on the risk of hypoglycaemia in infants of insulin dependent diabetic mothers. Acta Paediatr Scand 1985; 74 268-73.

41 Hawdon JM, Aynsley-Green A, Alberti KGMM, Ward Platt MP. The role of pancreatic insulin secretion in neonatal glucoregulation. 1. Healthy term and preterm infants. Arch Dis Child 1993; 68: 274-9.

42 Bhowmick SK, Lewandowski L. Prolonged hyperinsulinaemia and hypoglycaemia in an asphyxiated small for gestation infant. Case management and literature review. Clin Pediatr (Phila) 1989; 28: 575-8. 